\title{
The empty sella syndrome
}

\author{
Y. SACHDEV \\ M.D., M.A.M.S. \\ D. C. EVERED \\ B.Sc., M.D., M.R.C.P. \\ A. APPLEBY \\ M.B., B.S., D.M.R.D., F.R.C.R. \\ R. HALL \\ B.Sc., M.D., F.R.C.P.

\begin{abstract}
Endocrine Unit, Department of Medicine, Royal Victoria Infirmary, Newcastle upon Tyne NE1 4LP
\end{abstract}

\begin{abstract}
Summary
The empty sella syndrome (ESS) presents a varied clinical and radiographic picture. It may remain asymptomatic or may simulate an intrasellar growth thereby causing diagnostic and therapeutic problems. An air encephalogram (AEG) is required for diagnosis. The purpose of this paper is to review the clinical and radiological features of the ESS and to discuss the pathogenetic mechanisms involved.
\end{abstract}

\section{Introduction}

The pituitary gland is located in the sella turcica and is attached to the base of the brain by the pituitary stalk which passes through the diaphragma sellae, a thick layer of the dural membrane. Sometimes the diaphragma sellae is incomplete and the subarachnoid space extends into the pituitary fossa flattening the pituitary gland which forms a thin layer at the sellar base. Busch (1951) has called this the 'empty sella'. Alternatively it has been termed a 'subdiaphragm cistern', an 'intrasellar subarachnoid space' and an 'intrasellar cyst' (Caplan and Dobben, 1969).

\section{Pathogenesis}

The empty sella syndrome (ESS) is a distinct anatomical and radiographic entity. It is the result of two contributory factors: anatomic variation in the diaphragma sellae and the cerebrospinal fluid (CSF) pressure. Two distinct clinical types have been described.

Primary or idiopathic ESS. This is a benign condition occurring as a result of an anatomical variation in the diaphragma sellae. The incomplete diaphragma sellae allows the arachnoid to herniate through the diaphragmatic opening. In time, the herniated pouch may enlarge owing to hydrostatic CSF pressure and compress the pituitary gland against the sella which may itself be partially demineralized. The idiopathic ESS has usually been described from obese middle-aged women. Kaufman (1968) has mentioned instances of empty sella in association with pseudotumour cerebri, congestive cardiac failure, the Pickwickian syndrome of respiratory insufficiency, and conditions where the CSF pressure is raised, although it is uncertain whether these are all real associations. It may also be associated with the rupture of suprasellar cystic lesions through the diaphragm and with spontaneous necrosis of an intrasellar tumour (Hodgson et al., 1972).

Secondary ESS. This variety is associated with operation or irradiation on an intrasellar tumour resulting in tissue loss within the sella. Suprasellar structures including the optic chiasm are liable to herniate downwards into the sella or may be drawn into the sellar cavity by fibrous tissue. The sella is usually enlarged and is often demineralized by the intrasellar tumour.

\section{Clinical features}

In idiopathic ESS a history of frequent headaches and sinusitis is usual. Spontaneous, intermittent or persistent CSF rhinorrhoea is a common non-specific association and is considered to be due to the opening up of embryonic channels whenever there is a sudden increase in CSF pressure as in coughing or sneezing (Brisman, Hughes and Mount, 1969). Visual defects are conspicuously absent and symptoms of endocrine disorder are rare (Leading Article, 1973). Endocrine function is normal in about $75 \%$ of patients. In the others, impaired growth hormone (GH) secretion in response to hypoglycaemia and decreased secretion of gonadotrophins are the commonest abnormalities observed. In the secondary variety of ESS, endocrine dysfunction is commoner and differs in no way from that observed in pituitary tumours treated by operation or irradiation in which the ESS is absent. The sella is enlarged by the expanding intrasellar tumour with or without involvement of the optic chiasm. The extent of the visual defect depends upon the degree of herniation of the optic chiasm and whether it is 'pre-fixed' or 'postfixed' (Schaeffer, 1924). 


\section{Diagnosis}

A detailed endocrine history and tests of the hypothalamic-pituitary target organ axis are essential. The visual fields must be assessed by an experienced ophthalmologist. A skull X-ray with antero-posterior and lateral views and tomography of the fossa should be organized. In the ESS, the skull X-ray may show either a normal sella, a ballooned sella with normal dimensions or an enlarged globular sella with thinning of the dorsum sellae (Kaufman, 1968). However, proper delineation of the ESS is only possible by air encephalography. This is best performed taking a recumbent 'brow-up' view with $15-20^{\circ}$ extension of the canthomeatal line beyond the vertical. In the erect position, CSF may fill the sella and the empty sella may not be appreciated. Hence it is necessary to extend the head sufficiently for the CSF to escape and air to enter the sella (Fig. 1).

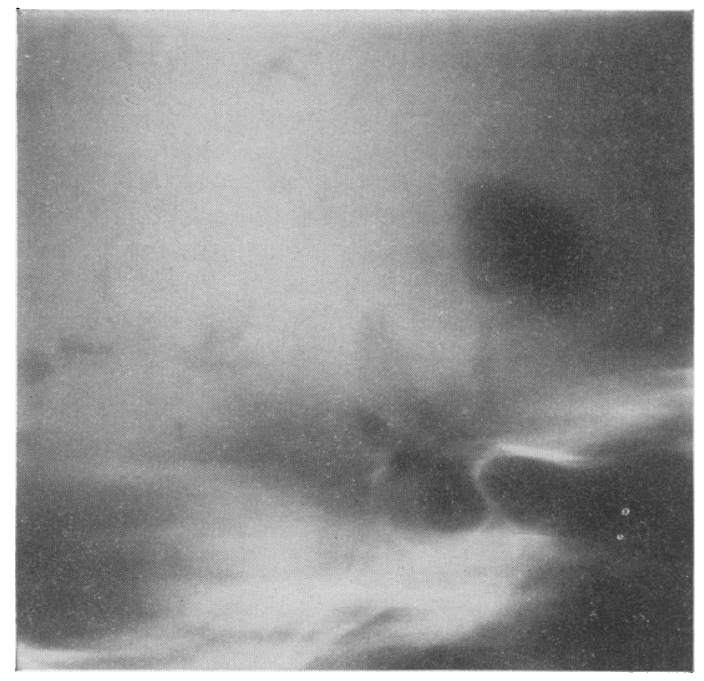

Fig. 1. Mid-line tomogram during the course of an air encephalogram showing the sella turcica largely filled with air. The air is continuous with the air in the basal cisterns.

\section{Discussion}

It has long been believed that the base of brain and pituitary stalk are lined with pia mater while the intrasellar portion of the pituitary gland is lined only with dura mater (Gray, 1954). Hughson (1924), however, claimed that the pituitary is invested by all three meningeal layers. Bailey (1932) concluded from his studies that a layer of pia mater surrounded the epithelial lobe and continued into the region of separation between the pars intermedia and the neural lobe. Wislocki (1937) studied a $160 \mathrm{~mm}$-long human fetus and found that the subarachnoid space ended in the form of a collar around the infundibulum. Schaeffer (1924) noted the opening in the diaphragma sellae to be variable in size, in some cases forming merely a peripheral rim of dura leaving a large hiatus in the centre. Such an aperture would obviously allow the subarachnoid space to herniate into the pituitary fossa and to form a loose sac within its confines thereby coming in contact with some portion of the pituitary. Bergland, Ray and Torack (1968) have suggested that when the diaphragmatic opening exceeds $5 \mathrm{~mm}$ in diameter there is a risk of development of such a space. They found that the pituitary was at least $2 \mathrm{~mm}$ shorter than its expected length in $23 \%$ of normal post-mortems and in some it was less than half the depth of sella. In such cases they found the ballooned-up subarachnoid space occupying the remainder of the sella. Other workers (Robertson, 1957; Engels, 1958; Notter, 1959; Di Chiro, 1961 ; Di Chiro and Nelson, 1962; Du Boulay, 1965) have also confirmed the existence of an intra-sellar subarachnoid space.

Busch (1951) has classified ESS in three subgroups depending on the appearance of the diaphragm and size of the aperture.

(i) Type 1-A. When the diaphragma sellae forms a complete covering and only allows passage of the pituitary stalk. In Type 1-B, where there is a slight funnel-shaped depression in the completely formed diaphragma sellae.

(ii) Type 2-A. Here the diaphragma sellae is incompletely closed with an opening $3 \mathrm{~mm}$ or less in diameter around the pituitary stalk. In Type 2-B, there is a funnel-shaped indentation towards the middle.

(iii) Type-3. In this variety, the diaphragma sellae forms a peripheral ring of tissue $2 \mathrm{~mm}$ or less with: (A) the pituitary gland freely exposed but covered with arachnoid membrane; (B) an indentation (often eccentric) of the pituitary gland; or (C) the pituitary gland flattened to the bottom.

The diagnosis of ESS can only be confirmed by pneumoencephalography, since clinically the condition may simulate an intrasellar growth especially when the visual fields are involved.

\section{References}

Balley, P. (1932) Structure of hypophysis cerebri of man and of common laboratory animals. In: Special Cytology, Vol. II (Ed. E. V. Cowdry), p. 771. Paul B. Hoeber Inc., New York.

Bergland, R.M., RAY, B.S. \& TORACK, R.M. (1968) Anatomical variation in the pituitary gland and adjacent structure in 225 human autopsy cases. Journal of Neurosurgery, 28, 93.

Brisman, R., Hughes, J.E.O. \& Mount, L.A. (1969) Cerebrospinal fluid rhinorrhoea and empty sella. Journal of Neurosurgery, 31, 538.

Busch, W. (1951) Die Morphologie der Sella turcica und ihre Beziehungen zur Hypophyse. Virchows Archiv für pathologische Anatomie und Physiologie und für klinische Medizin, 320, 437. 
Caplan, R.H. \& Dobben, G.D. (1969) Endocrine studies in patients with the 'empty sella syndrome'. Archives of Internal Medicine, 123, 611.

Dı Chiro, G. (1961) An Atlas of Detailed Normal Pneumoencephalographic Anatomy, p. 302. Charles C. Thomas, Springfield, Illinois.

Di Chiro, G. \& Nelson, K.B. (1962) The volume of the sella turcica. American Journal of Roentgenology, Radium Therapy and Nuclear Medicine, 87, 989.

Du Boulay, G.H. (1975) Principles of X-ray Diagnosis of the Skull, p. 145. Butterworths, London.

ENGELS, E.P. (1958) Roentgenographic demonstration of a hypophyseal subarachnoid space. American Journal of Roentgenology, Radium Therapy and Nuclear Medicine, 80, 1001.

Gray, H. (1954) Anatomy of the Human Body, p. 1421. Lea and Febiger, Philadelphia.

Hodgson, S.F., Randall, R.V., Holman, C.B. \& MaC-
CARThY, C.S. (1972) Empty sella syndrome (report of 10 cases). Medical Clinics of North America, 56, 897.

Hughson, W. (1924) Meningeal relations of hypophysis cerebri. Bulletin of the Johns Hopkins Hospital, 35, 232.

KaUfman, B. (1968) The 'empty' sella turcica-a manifestation of the intrasellar subarachnoid space. Radiology, 90, 931.

LeADING ARTICLE (1973) Empty sella. Lancet, i, 925.

NotTer, G. (1959) A technique for destruction of the hypophysis using $\mathrm{Y}^{90}$ spheres. A radiologic, endocrine and histologic study. Acta radiologica, Suppl. 184.

Robertson, E.G. (1957) Pneumoencephalography, p. 214, Charles C. Thomas, Springfield, Illinois.

SchaEfFer, J.P. (1924) Some points in regional anatomy of optic pathways with special reference to tumors of hypophysis cerebri and resulting ocular changes. Anatomical Record, 28, 243.

WisLOCKI, G.B. (1937) Meningeal relations of hypophysis cerebri. American Journal of Anatomy, 61, 95. 